\title{
К ВОПРОСУ КРИМИНАЛИЗАЦИИ ПОСЯГАТЕЛЬСТВ НА ПРАВА И ИНТЕРЕСЫ ПРАВООБЛАДАТЕЛЕЙ СРЕДСТВ ИНДИВИДУАЛИЗАЦИИ ТОВАРОВ И УСЛУГ
}

Аннотация. У авторов и правообладателей вызывает тревогу производство и реализация контрафактной продукиии, масштабы которой представляют серьезную угрозу экономической безопасности России. Доля подделок увеличивается от обуви и одеждь до материальных носителей аудио- видеоинформации. Особую озабоченность вызывает проблема контрафактности лекарственных средств. Вместе с тем, среди ученых, занимающихся рассматриваемой проблемой, есть мнение, что деяния, предусматривающее уголовную ответственность за незаконное использование товарного знака (cm. 180 УК РФ), не соответствуют реальньм потребностям общества в уголовном запрете. В теории уголовного права этот вопрос является достаточно спорным, к сожалению, на сегодняшний день к единому мнению по нему так и не пришли. В работе автором делается попытка показать обусловленность криминализации рассматриваемых деяний. Исследование проводилось на основе совокупности общенаучных и социильно-юридических методов. Для решения отдельных задач исследования использовались следующие методы: статистический, аналитический, сравнительно-правовой и другие. В результате проведенного исследования автор приходит к следуюшим выводам: деяния, посягаюшие на незаконное использование чужого товарного знака, знака обслуживания, наименования места происхождения товара или сходных с ними обозначений для однородных товаров, отвечают основаниям их криминализачии в связи с высокой общественной опасностью и их относительной распространенностью. Вместе с тем, незаконное использование предупредительной маркировки в отношении не зарегистрированного в Российской Федерачии средства индивидуализации не отвечает основаниям (условиям) криминализации деяний: ст. 1225 ГК РФ не определяет ее как результат интеллектуальной деятельности, следовательно, не ясно, чьи права нарушены.

Ключевые слова: Общественная опасность, криминализащия, правообладатель, права правообладателя, товарный знак, знак обслуживания, место происхождения товара, предупредительная маркировка, предварительный сговор, организованная группа.

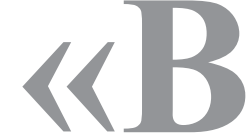

условиях отказа от директивного планирования экономического и социального развития страны и перехода Российской Федерации к рыночной экономике» ${ }^{1}$ важным ее элементом стали объекты промышленной соб-

\footnotetext{
Лукьянова В.Ю. К вопросу о правовой природе технических условий // Законодательство и экономика. 2014. N 4.
}

ственности - средства индивидуализации товаров и услуг (товарные знаки, знаки обслуживания и наименования мест происхождения товаров), которые выполняют роль по индивидуализации предприятий и предпринимателей, а также производимых ими товаров и услуг. Они призваны: обеспечить потребителя информацией о товарах и услугах, которая содержится на товарных знаках, 
знаках обслуживания и наименованиях мест происхождения товара; дают возможность потребителю отличить товар одного производителя от аналогичных товаров другого производителя; на внутреннем рынке они выполняют функции по стимулированию покупательской активности потребителя в отношении товаров конкретного производителя, способствуют продвижению и реализации товаров за рубежом.

В теории уголовного права «в связи с совершенствованием действующего уголовного законодательства Российской Федерации, его развития и обновления внимание специалистов привлечено к выяснению вопросов, касающихся обусловленности уголовно-правового запрета некими причинами, побуждающими законодателя устанавливать либо отменять уголовную наказуемость тех или иных общественно опасных деяний.» ${ }^{1}$. В процессе этой работы появилась точка зрения, согласно которой, ряд деяний, признаваемых законодателем преступными, не соответствует реальным потребностям общества в уголовном запрете, к их числу отнесена и ст. 180 УК РФ (незаконное использование товарного знака) $)^{2}$. К сожалению, автор не обосновывает, в силу каких причин ст. 180 УК РФ, по его мнению, не отвечает этому требованию. Данная позиция нами не разделяется. В этой связи возникает вопрос: была ли необходимость в криминализации рассматриваемого деяния, если на практике соответствующий состав преступления имеет низкую применяемость?

\footnotetext{
1 Коробеев А.И. Современная российская уголовноправовая политика: вялотекущая эволюция или радикальное реформирование уголовного законодательства / Уголовная политика и право в эпоху перемен. Материалы международной научно-практической конференции посвященной памяти профессора П. С. Дагеля. Владивосток. Изд-во Дальневосточного университета. 2010. С. 30, 31. 364 c.

2 Коробеев А.И. Современная российская уголовноправовая политика: вялотекущая эволюция или радикальное реформирование уголовного законодательства. C. 32.364 c.
}

Попытаемся ответить на него, и обратимся к теории криминализации общественно опасных деяний.

Известно, что в теории криминализации (декриминализации) деяний существуют следующие условия (основания): экономические, политические, социально-психологические и криминологические.

К криминологическим условиям (основаниям) относятся общественная опасность деяния; его относительная распространенность; невозможность воздействия на определенный вид общественно опасного поведения другими, не уголовно-правовыми средствами; учет возможностей системы уголовной юстиции; допустимость введения уголовно-правового запрета с точки зрения норм международного права; социальная адекватность криминализации, и ряд других условий ${ }^{3}$.

Уголовно-правовой анализ (ст. 180 УК РФ) показывает, что норма предусматривает ответственность за два разных преступления: незаконное использование чужого товарного знака, знака обслуживания, наименования места происхождения товара или сходных с ними обозначений (ч.1); незаконное использование предупредительной маркировки в отношении не зарегистрированного в Российской Федерации товарного знака или наименования места происхождения товара (ч. 2); (ч.3) предусматривает наказание за указанные выше деяния, совершенные в организованной форме (группой лиц по предварительному сговору или организованной группой).

Известно, что уголовно наказуемыми являются действие (бездействие) с повышенной степенью общественной опасности.

Напомним, общественная опасность является материальным признаком преступления, объясняющим необходимость признания деяния преступным. То сеть, деяние нарушающее

\footnotetext{
3 Прозументов Л. М. Криминологические условия криминализации и декриминализации. Вестник Томского Государственного Университета. 2012. № 4 (6).
} 
наиболее ценные для общества отношения и влекущие для него (общества) опасность. (ч. 1 ст. 2 УК РФ).

Общественная опасность незаконного использования чужого товарного знака, знака обслуживания, наименования места происхождения товара или сходных с ними обозначений (ч. 1. ст. 180 УК РФ), выражается в причинении крупного ущерба правообладателям; причиняют серьезный экономический ущерб государству связанный с сокрытием от налогообложения весьма больших доходов; создают угрозу здоровью населения, поскольку производителей контрафакта не особенно заботит качество продукции, на первом месте у них прибыль

Криминальные деяния участников рынка отражаются не только на правах производителей (правообладателей), лишающихся прибыли при осуществлении недобросовестной конкуренции со стороны лиц незаконно использующих, в нарушении ст. 1489 ГК РФ зарегистрированный ими товарный знак, знак обслуживания, но и на их репутации. Кроме того, от действий этих лиц страдает репутация государства в целом, а также его финансовые интересы. Деятельность рассматриваемых лиц в сфере незаконного использования результатов интеллектуальной деятельности порождает у граждан недоверие к власти, девальвацию значения закона как инструмента регулирования социально-экономической жизни.

Вместе с тем с ценностных позиций блага (интереса), которому причиняется вред, не все случаи нарушения незаконного использования товарного знака и знака обслуживания подлежат уголовному запрету.

Проиллюстрировать все вышесказанное можно следующими примерами.

«В мире хорошо известна французская фирма ВIC - крупнейший производитель канцелярских принадлежностей. В последнее время эта фирма несет значительные потери. В Китае, Индии, Арабских эмиратах возникла целая индустрия подделок под ВIС. Эта про- дукция реализуется и в России. По разным оценкам в России реализовано более 120 млн. только фальшивых ручек ${ }^{1} »$.

По оценкам Международной торговой палаты, торговля контрафактной продукцией во всем мире составляет 5-7\% от объема всей международной торговли товарами, что в абсолютных величинах составляет порядка 500 млрд. долл. США в год².

«По официальным данным Роспатента, оборот всей поддельной продукции, включая товары народного потребления, на российском рынке составляет 80-100 млрд. руб. в год, в результате чего экономика недосчитывает 1,5 млн. рабочих мест, а госбюджет30 млрд. руб. По неофициальным данным оборот контрафакта в России значительно больше и оценивается в 150-200 млрд. руб. в год. По данным Всемирной организации интеллектуальной собственности (ВОИС), одни только прямые убытки от контрафактной продукции и пиратства в мире превышают сегодня 100 млрд. долл. в год. По данным ГИАЦ МВД России в 2008 году правоохранительными органами выявлено 13,0 тыс. преступлений, связанных с производством и оборотом фальсифицированных и контрафактных товаров ${ }^{3}$. Всего в 2008 году выявлено и признано судами 10,2 миллиона единиц контрафактной продукции ${ }^{4} »$.

Еще один пример из практики: патентноправовая компания «Сармат» провела анализ

\footnotetext{
${ }^{1}$ http://newasp.omskreg.ru

2 Ворожейкина А.Г., Юсуфов А.Ш. Рынок контрафактной продукции и его структура в России и за рубежом // Интеллектуальная собственность. Контрафакт. Актуальные проблемы теории и практики: сб. науч. труд. под ред. д-ра юрид. наук В.Н. Лопатина. Т. 2.- М.: Издательство Юрайт, 2009. С. 49.

3 О состоянии правовой охраны и защиты интеллектуальной собственности в Российской Федерации в 2008 году. Аналитический доклад / под ред. д-ра юрид. наук В. Н. Лопатина, М., РНИИИС, 2009, 325 с.

4 Костин А.В. Оценка убытков правообладателей товарных знаков от контрафакции. ... Дисс. канд. юрид. наук. М. 2009. С. 3.
} 
шести крупных предприятий кондитерской отрасли Кубани. Как выяснилось, из 600 наименований используемых кондитерскими компаниями Краснодарского края, при маркировке своей продукции, более 70\% зарегистрированы на имя иных крупных производителей. Объектом воровства интеллектуальной собственности - товарных знаков, становятся в основном иностранные и московские компании, например холдинг «Объединенные кондитеры». Их бренды раскручивались десятилетиями, поэтому успех контрафактного производства обеспечен. И лишь 1,77\% зарегистрировано на имя этих производителей ${ }^{1}$.

Таким образом, с точки зрения рассмотренного основания уголовно-правовой запрета этого деяния, является обоснованным.

Что касается обоснованности криминализации деяния, предусмотренного ч. 2 рассматриваемой статьи, деятельность законодателя в данном случае, на наш взгляд, представляется не совсем безупречной.

Анализ этой нормы с учетом ее бланкетного содержания показывает, что наказание наступает за незаконное использование предупредительной маркировки. Вместе с тем, в соответствии с положениями четвертой части ГК РФ (ст. 1225) она (предупредительная маркировка) не является результатом интеллектуальной деятельности, следовательно, не подлежит правовой охране. Как верно отмечается И. А. Клепицким и Л.К. Никитиной ${ }^{2}$, вопрос в том, чьи права могут быть в таком случае нарушены, остается неясным. В такой ситуации говорить о причинении крупного ущерба кому-либо, а также о высокой степени общественной опасности деяния затруднительно. В этой

\footnotetext{
http://www.sarmat-tm.ru. Запрос производился 6 июня 2014 года.

2 Никитина Л.К. Основные направления оптимизации уголовного законодательства об ответственности за незаконное использование товарного знака. Общество и право. 2010, № 1. С. 172-177.; Клепицкий И. А. Система хозяйственных преступлений. М., 2005.
}

связи, полагаем, рассматриваемое деяние следует декриминализировать.

И дело на наш взгляд даже не в том, что диспозиция (ч. 2) рассматриваемой статьи способствует неверному ее толкованию и как следствие затрудняет применение, или «... при наличии соответствующих признаков одномоментно перерастает из аморального поступка в преступление» ${ }^{3}$. Просто рассматриваемое деяние не представляет общественной опасности, - не нарушает чьи - либо права.

По данным статистики в период с 2000 по 2010 г. г. число осужденных по рассматриваемой части статьи составило пять человек ${ }^{4}$. Представляется комментарии излишни.

Обозначенная позиция находит свое подтверждение в юридической литературе.

Вместе с тем, необходимо поддержать авторов, которые ратуют за введение уголовной защиты следующих объектов интеллектуальной собственности: фирменных наименований и коммерческих обозначений п. 13 и 16 ч. 1 ст. 1225 ГК РФ. Полагаем, нет смысла повторно обосновывать необходимость такой защиты, в связи с тем, что это сделано в работе Л.Н. Никитиной.

В 2001 году ст. 180 УК РФ была дополнена нормой предусматривающей ответственность за деяния предусмотренный ч. 1 и 2 указанной статьи совершенных группой лиц по предварительному сговору или организованной группой ${ }^{5}$, санкция ее была увеличена до шести лет.

\footnotetext{
3 Никитина Л.К. Основные направления оптимизации уголовного законодательства об ответственности за незаконное использование товарного знака. С. 173.

4 «О состоянии правовой охраны и защиты интеллектуальной собственности в Российской Федерации в 2010 году» Аналитический доклад (под ред. Лопатина В.Н. М., Издательство Совета Федерации, 2001.С. $307.438 \mathrm{c}$.

5 Ф3 от 17.11.2001№ 144-Ф3 «О внесении изменений и дополнений в Уголовный кодекс Российской Федерации и Уголовно-процессуальный кодекс РСФСР». «Росс. Газ», 2001. № 227.
} 
Рассматриваемый состав преступления стал квалифицированным, т. е. представляет собой повышенную степень общественной опасности по сравнению с основными составами ст. 180 УК РФ. Несомненно, ущерб от преступной деятельности правообладателм и государству от группы лиц, совместивших свои усилия в преступной деятельности, несоизмеримо больше чем от одного лица.

Повышая ответственность по ч. 3 ст. 180 УК РФ до шести лет лишения свободы, полагаем, законодатель преследовал идею повышения эффективности борьбы с такими преступлением. Однако на практике наказание в виде лишения свободы за такое преступление назначается судами крайне редко. Червоткин А. С. по этому поводу пишет: «Практика показывает, что значительное количество уголовных дел рассматриваемой категории - до 25\% -судами прекращается в основном за примирением сторон, а также в связи с деятельным раскаянием (ст. 75 и 76 УК РФ)» ${ }^{1}$. В этой связи возникает вопрос об адекватности санкции общественной опасности преступления.

Ещё одним из оснований криминализации, признания деяния общественно опасны, является его относительная распространенность ${ }^{2}$ (дан-

\footnotetext{
1 Комментарий к постановлениям Пленума Верховного Суда Российской Федерации по уголовным делам (2-е издание, переработанное и дополненное) (под ред. М.В. Лебедева) НОРМА, 2008.

2 К числу важнейших оснований (факторов, принципов, критериев, условий) определяющих потребность общества в криминализации того или иного деяния на ряду с другими основаниями, многие известные ученые правоведы относили и степень распространенности этих деяний. Например, Дагель П. С. Условия установления уголовной наказуемости. Правоведение, 1975, № 4. С.67-74; Гальперин И. М. Уголовная политика и уголовное законодательство./Основные направления борьбы с преступностью. М. Юрид. Лит., 1975. С. 58. Курляндский В.И. Уголовная политика: дифференциация и индивидуализация уголовной ответственности. В кн.: Основные направления борьбы с преступностью. C. 81 .
}

ное основание входит в юридико-криминологическую группу оснований уголовно-правового запрета $\left.{ }^{3}\right)^{4}$. То есть деяние (антиобщественное поведение) должно быть достаточно распространено.

Анализ состояния преступности в сфере интеллектуальной собственности показывает, что нарушения уголовного законодательства о незаконном использовании товарного знака (ст. 180 УК РФ) носит весьма распространенный характер, встречаются повсеместно и достаточно часто.

Так, за последние шесть лет с 2008 по 2013 гг., выявлены тенденции снижения (2008-2011 гг.) и роста (2012-2013 гг.) числа зарегистрированных преступлений, квалифицируемых по ст. 180 УК РФ, соответственно с 566 до 383, и с 413 до $485^{5}$. Темп снижения преступлений составил $18,5 \%$, и роста — на 17 , 4\%. За указанный период времени было выявлено 1343 лица совершивших это преступление. В 2011-2012 гг. в суд направлено 415 уголовных дел.

Таким образом, совокупные перечисленные сведения характеризуют отдельные стороны таких количественных показателей преступности, как объем и динамика.

Приведенные сведения на взгляд автора, не позволяют сделать вывод о благоприятной криминальной ситуации, связанной с совер-

\footnotetext{
3 Не является тайной, что в теории уголовного права остается проблемой основания уголовно-правового запрета, т.е., правообразующих факторов обусловливающих признания деяния преступным и уголовно наказуемым.

4 Коробеев А. И. Современная российская уголовноправовая политика: вялотекущая эволюция или радикальное реформирование уголовного законодательства. C. $69.267 \mathrm{c}$

5 По данным официального Интернет-сайта Министерства внутренних дел РФ. URL: http://www.mvd.ru (дата обращения: 12.03.2014); «О состоянии правовой охраны и защиты интеллектуальной собственности в Российской Федерации в 2010 году» Аналитический доклад (под ред. Лопатина В. Н. М., Издательство Совета Федерации, 2001.С. 305. 438 с.
} 
шением указанного преступления. Даже учтенная преступность позволяет сделать такой вывод. Хотя известно, что среди криминологов существует мнение, « . . . что в настоящее время статистика о зарегистрированных отдельных видах преступлений перестала быть достоверным источником информации о преступности. Более того, в криминологической литературе стало уже привычным сравнение зарегистрированной преступности с видимой частью айсберга» ${ }^{1}$.

«Выборочные опросы граждан, предпринимателей, а также сотрудников органов внутренних дел позволяют утверждать, что масштабы незаконного использования товарного знака больше тех, которые отражаются в официальной статистике. Наибольшую часть латентных преступлений составляют деяния, о которых знает достаточно широкий круг лиц, включая потребителей товаров. Последних особенно привлекает невысокая стоимость приобретаемой продукции, что позволяет сбытчикам не беспокоиться о реализации производимых товаров и сохранять (либо стремительно расширять) масштабы преступной деятельности» ${ }^{2}$.

О состоянии преступности, связанной с незаконным использованием товарного знака (ст. 180 УК РФ), в мае — июле 2014 года проводился опрос ${ }^{3}$ среди 82 жителей При-

\footnotetext{
1 Алексеенко Н. Н. Уголовно-правовая и криминологическая характеристика преступлений в сфере регистрации незаконных сделок с землей: монография. М.: Юрист, 2013. 152 с.

2 Жайворонок А.В. Незаконное использование товарного знака: криминологическое и уголовно-правовое исследование. Автореф. дисс. канд. юрид. наук. М., 2010. C.17.

3 Опрос проводился сотрудниками ИСМИ «Аналитик» в мае-июне 2014 года, среди жителей Волгограда (Волгоградской области), http: www.socio-researh.ru, а также сотрудников территориальных подразделений УБЭПиК УМВД по Приморскому краю (оперативные сотрудники и следователи), проходивших переподготовку во Владивостокском филиале ДВЮИ МВД РФ в мае 2014 г., всего опрошено 112 человек.
}

морского края и 30 человек проживающих в г. Волгограде и Волгоградской области. Опрос показал следующие результаты. 47,5\% жителей Приморского края считают, что преступления с незаконным использованием товарного знака распространено в их регионе не значительно; 35,5\% жителей полагают, что распространено сильно; 10,9\% полагают, что вообще не распространено.

В г. Волгограде и его области было опрошено 30 человек, из которых 33,3\% считают, что такое преступление в их регионе имеет незначительное распространение; 56,6\% жителей полагают сильно распространено; вообще не распространено считают 6,7\%; затрудняются с ответом 3,3\%.

По данным «Главного управления МВД России по Московской области в настоящее время по оценкам независимых экспертов удельный вес «поддельной продукции» по отдельным видам товаров колеблется от 40\% до $80 \%$. Уровень контрафактности достигает: в области программного обеспечения до $85 \%$; в сфере оборота аудио-видеопродукции - свыше $80 \%$; по изделиям бытовой химии- до 43\%; в сфере производства и реализации пищевых продуктов - до 45\%. Сначала года сотрудниками Управления и районными отделами экономической безопасности и противодействия коррупции на территории Московской области выявлено 205 преступлений, связанных с оборотом фальсифицированной продукции, в том числе за нарушения авторских и смежных прав (ст. 146 УК РФ) - 53, за незаконное использование товарного знака (ст. 180 УК РФ) - 10.

Совокупный ущерб, заявленный правообладателями по выявленным фактам незаконного производства и сбыта поддельной продукции, за указанный период составил более 200 миллионов рублей.

Так, например, в марте 2013 года в Орехово-Зуевском районе пресечена деятельность пяти незаконных цехов по производству спортивной одежды с использованием лейб- 
лов и символики известных торговых марок. На территории производств изъято свыше 2000 единиц готовой контрафактной продукции.

В мае 2013 года в г. Балашиха на территории бывшей фабрики, выявлено нелегальное производство одежды всемирно известных брендов. Всего сотрудниками полиции было изъято более 10000 поддельных курток, спортивных костюмов и маек ${ }^{1}$.». При этом начальник оперативно-разыскной части ЭБиПК № 1 ГУ МВД России по Московской области Н. Лазебный отмечает, что «этот вид преступности отличается высокой латентностью² ${ }^{2}$. О некоторых ее причинах написано выше.

Известно, что уголовная ответственность является наиболее репрессивной формой государственного принуждения и прибегать к ней необходимо, когда защитить общество от общественно опасного поведения лица другими средствами (под другими понимаются правовые средства, такие как нормы гражданского, административного и других отраслей права, нормы которых оказались не эффективными в противодействии с определенными видами общественно опасного поведения) не будет эффективным.

В связи, с этим возникает вопрос, соответствует ли решение законодателя о криминализации деяний, совершенных в отношении средств индивидуализации товаров и услуг, (ст. 180 УК РФ) рассматриваемому критерию?

По действующему законодательству за нарушения средств индивидуализации товаров и услуг предусмотрено три вида ответственности: гражданско-правовая, административная и уголовная. Как видно,

\footnotetext{
1 Итоги пресс-конференции на тему: «Борьба с незаконным оборотом контрафактной продукции на территории московской области» 27 июня 2013 Главного управления МВД России по Московской области. http://50.mvd.ru/press/reliaze/item/

2 Смотри там же. http://50.mvd.ru/press/reliaze/item/
}

действия законодателя носят последовательный характер в борьбе с такими видами правонарушений.

Уголовная ответственность за деяния, предусмотренные ст. 180 УК РФ наступают в случае совершения деяний неоднократно или с причинением крупного ущерба правообладателю. То есть общественная опасность гораздо выше, чем у административного проступка.

Например, встречаются случаи когда «в действиях правонарушителя фальсификация и контрафакция могут содержаться одновременно. Так, если фальсифицированное лекарство по своему составу не соответствует оригинальному (что необходимо подтвердить проведением химической экспертизы) и произведено под чужим товарным знаком без разрешения правообладателя, то оно является одновременно фальсифицированным и контрафактным. Такие действия правонарушителей необходимо квалифицировать при наличии условий, предусмотренных уголовным законом, по совокупности преступлений по ст. 171 и 180 УК РФ. Например, в Республике Мордовия по указанным составам преступлений были привлечены к уголовной ответственности и осуждены лица за изготовление и реализацию фальсифицированных и контрафактных лекарственных препаратов «ампицилина натриевая соль» и «циклофосфан», на упаковках которых было указано фармацевтическое предприятие ОАО «Биохимик» ${ }^{3}$.

В связи с этим, представляется, игнорирование этого обстоятельства приведет к снижению эффективности борьбы с этим видом общественно опасного поведения в целом. Вместе с тем, следует отметить, на наш взгляд, законодатель завысил, при чем необоснованно, степень общественной опасности

\footnotetext{
3 Горелик А., Мазеин В. Практика возбуждения уголовных дел по фактам производства и распространения фальсифицированных лекарственных средств. // Право и жизнь. 2007. № 113 (8). C. 21-26. http://www.pandia.ru/
} 
(ч. 2) этой статьи. Полагаем за деяния, предусмотренные этой нормой следует привлекать к административной ответственности.

Еще одним криминализационным критерием является учет исторического и международного опыта в области криминализации (декриминализации) таких же либо подобных деяний.

Говоря о международном опыте борьбы с незаконным использованием чужого товарного знака, следует еще раз отметить, что в странах дальнего и ближнего зарубежья, незаконное использование средства индивидуализации товаров и других средств индивидуализации и их производителей уголовно наказуемо. Разница заключается в конструкции нормы закона предусматривающей ответственность за рассматриваемые деяния и ее санкции, и самого нормативного акта, в котором содержаться запреты той или иной страны. Например, в ФРГ ответственность за рассматриваемое преступление устанавливается федеральным Законом от 9 мая 1961 г. «О товарных знаках» (в ред. от 29 января 1979 г.) (далее - Закон). Согласно § 26 Закона уголовная ответственность установлена «за незаконную маркировку чужим товарным знаком своих товаров или их упаковки; использование в своих рекламных материалах товарного знака другого лица; ввод в оборот товаров, обозначенных товарным знаком противоправным способом, а равно за хранение товаров на складе» ${ }^{1}$.

В КНР такая норма содержится в уголовном законе. Статья 214 УК КНР за продажу продукции с заведомо поддельной торговой маркой при сравнительно крупной сумме реализации предусматривает наказание в виде лишения свободы на срок до 3 лет или кратковременным арестом, или в качестве самостоятельного наказания штрафом. В ст. 214 УК КНР предусматривается квалифи-

\footnotetext{
1 Калиновский В.Е. Охрана товарного знака в ФРГ. M. 1984. C.40
}

цированный состав - продажа продукции на крупную сумму. Соответственно наказание предусмотрено в виде лишения свободы на срок от 3 до 7 лет и штрафом.

Согласно ст. 215 УК КНР за подделку, самовольное изготовление символики с чужой торговой маркой или продажу поддельной, самовольно изготовленной символики с торговой маркой при отягчающих обстоятельствах, предусмотрено наказание в виде лишения свободы на срок до 3 лет, краткосрочного ареста или надзора, а также одновременно или в качестве самостоятельного наказания - штраф. За это же деяние, совершенное при особо отягчающих обстоятельствах, наказание - лишение свободы на срок от 3 до 7 лет или штраф ${ }^{2}$.

Следовательно, по УК КНР за преступления против интеллектуальной собственности предусматриваются более суровые наказания, чем в России и странах Европы, в тоже время, по нашему мнению, конструкция нормы предусматривающей ответственность за рассматриваемое правонарушение в ФРГ, является более продуманной в части, касающейся правоприменения, чем в Российской Федерации. В § 26 Закона нет таких криминообразующих признаков как: причинение крупного ущерба или неоднократности соответствующих действий.

В связи с изложенным, представляется, что сегодня необходимо совершенствовать законы, а также формы и методы борьбы с данным видом преступности. Кроме того разъяснять потребителям опасность пользования контрафактной продукцией, привлекая для этой работы самих правообладателей и СМИ. Ведь если упадет спрос, снизится и предложение ${ }^{3}$.

\footnotetext{
Уголовный кодекс Китайской Народной Республики / Под ред. А. И. Коробеева. Перевод Д. В. ВичиковаСПб.: Юридический центр Пресс. 2001. С. 147-148.

3 Бренд «Дети подземелья» Щит и Мечь от 14.07.2013 http://www.ormvd.ru
} 
Таким образом, на наш взгляд проведенное исследование позволяет говорить, что в общем и целом криминализация деяний, посягающих на средства индивидуализации товаров и услуг, социально обусловлены.

Однако, полагаем, что декриминализации подлежит деяние за незаконное использование предупредительной маркировки в отношении незарегистрированного в России товарного знака или наименования места происхождения товара. Представляется за рассматриваемое деяние следует предусмотреть административную ответственность.

\section{Библиография}

1. Алексеенко Н.Н. Уголовно-правовая и криминологическая характеристика преступлений в сфере регистрации незаконных сделок с землей: монография. М.: Юрист, 2013. 152 с.

2. Бренд «Дети подземелья» Щит и Мечь от 14.07.2013 http://www.ormvd.ru

3. Ворожейкина А.Г., Юсуфов А.Ш. Рынок контрафактной продукции и его структура в России и за рубежом // Интеллектуальная собственность. Контрафакт. Актуальные проблемы теории и практики: сб. науч. труд. под ред. д-ра юрид. наук В. Н. Лопатина. Т. 2.- М.: Издательство Юрайт, 2009. С. 49.

4. Гальперин И.М. Уголовная политика и уголовное законодательство./Основные направления борьбы с преступностью. М. Юрид. Лит. 1975. С. 58.

5. Горелик А., Мазеин В. Практика возбуждения уголовных дел по фактам производства и распространения фальсифицированных лекарственных средств. // Право и жизнь. 2007. № 113 (8). С. 21-26.

6. Дагель П.С. Условия установления уголовной наказуемости.// Правоведение, 1975, № 4. С.67-74.

7. Жайворонок А.В. Незаконное использование товарного знака криминологическое и уголовно-правовое исследование. Автореф. дисс. ... канд. юрид. наук. М., 2010. С.17.

8. Итоги пресс-конференции на тему: «Борьба с незаконным оборотом контрафактной продукции на территории московской области» 27 июня 2013 Главного управления МВД России по Московской области. http://50.mvd.ru/press/reliaze/item/ (дата обращения 2 июня 2014 года).

9. Калиновский В. Е. Охрана товарного знака в ФРГ. М. 1984. С.40

10. Клепицкий И. А. Система хозяйственных преступлений. М., 2005. \{Электронный ресурс\} Доступ из справ. - правовой системы ПС «КонсультантПлюс».

11. Костин А. В. Оценка убытков правообладателей товарных знаков от контрафакции. дисс. канд. юрид. наук. М. 2009. С. 3.

12. Комментарий к постановлениям Пленума Верховного Суда Российской Федерации по уголовным делам (2-е издание, переработанное и дополненное) (под ред. М.В. Лебедева) HOPMA, 2008.

13. Коробеев А.И. Современная российская уголовно-правовая политика: вялотекущая эволюция или радикальное реформирование уголовного законодательства?/ Уголовная политика и право в эпоху перемен. Материалы международной научно-практической конференции посвященной памяти профессора П. С. Дагеля. Владивосток. Изд-во Дальневосточного университета. 2010. С. 30, 31. 364 с.

14. Курляндский В.И. Уголовная политика: дифференциация и индивидуализация уголовной ответственности. В кн.: Основные направления борьбы с преступностью. С. 81. 
15. Лукьянова В. Ю. К вопросу о правовой природе технических условий // Законодательство и экономика. 2014. № 4.

16. Никитина Л. К. Основные направления оптимизации уголовного законодательства об ответственности за незаконное использование товарного знака. Общество и право. 2010, № 1. С. 172-177.

17. О состоянии правовой охраны и защиты интеллектуальной собственности в Российской Федерации в 2008 году. Аналитический доклад / под ред. д-ра юрид. наук В. Н. Лопатина, М., РНИИИС, 2009, 325 С.

18. О состоянии правовой охраны и защиты интеллектуальной собственности в Российской Федерации в 2010 году. Аналитический доклад /под ред. Лопатина В. Н. М. Издательство Совета Федерации, 2009.С. 307. 438 с.

19. По данным официального Интернет-сайта Министерства внутренних дел PФ. URL: http:// www.mvd.ru (дата обращения: 12.03.2014).

20. Прозументов Л. М. Криминологические условия криминализации и декриминализации. Вестник Томского Государственного Университета. 2012. № 4 (6)

21. http://www.sarmat-tm.ru. Запрос производился 6 июня 2014 года

22. Уголовный кодекс Китайской Народной Республики /Под ред. А. И. Коробеева. перевод Д.В. Вичикова СПб.: Юридический центр Пресс. 2001. С. 147-148.

23. Федеральный закон от 17.11.2001№ 144-Ф3 «О внесении изменений и дополнений в Уголовный кодекс Российской Федерации и Уголовно-процессуальный кодекс РСФСР» «Российская газета», 2001. № 227.

\section{References (transliterated)}

1. Alekseenko N. N. Ugolovno-pravovaya i kriminologicheskaya kharakteristika prestuplenii v sfere registratsii nezakonnykh sdelok s zemlei: monografiya. M.: Yurist, 2013. 152 s.

2. Brend «Deti podzemel'ya» Shchit i Mech» ot 14.07.2013 http://www.ormvd.ru

3. Vorozheikina A. G., Yusufov A. Sh. Rynok kontrafaktnoi produktsii i ego struktura v Rossii i za rubezhom// Intellektual'naya sobstvennost». Kontrafakt. Aktual'nye problemy teorii i praktiki: sb. nauch. trud. pod red. d-ra yurid. nauk V. N. Lopatina. T.2.— M.: Izdatel'stvo Yurait, 2009. S. 49.

4. Gal'perin I. M. Ugolovnaya politika i ugolovnoe zakonodatel'stvo./Osnovnye napravleniya bor'by s prestupnost'yu. M. Yurid. Lit. 1975. S. 58.

5. Gorelik A., Mazein V. Praktika vozbuzhdeniya ugolovnykh del po faktam proizvodstva i rasprostraneniya fal'sifitsirovannykh lekarstvennykh sredstv. // Pravo i zhizn». 2007. № 113 (8). S. 21-26.

6. Dagel» P. S. Usloviya ustanovleniya ugolovnoi nakazuemosti.// Pravovedenie, 1975, № 4. S.67-74.

7. Zhaivoronok A. V. Nezakonnoe ispol'zovanie tovarnogo znaka kriminologicheskoe i ugolovnopravovoe issledovanie. Avtoref. diss. ... kand. yurid. nauk. M., 2010. S.17.

8. Itogi press-konferentsii na temu: «Bor'ba s nezakonnym oborotom kontrafaktnoi produktsii na territorii moskovskoi oblasti» 27 iyunya 2013 Glavnogo upravleniya MVD Rossii po Moskovskoi oblasti. http://50.mvd.ru/press/reliaze/item/ (data obrashcheniya 2 iyunya 2014 goda).

9. Kalinovskii V.E. Okhrana tovarnogo znaka v FRG. M. 1984. S.40

10. Klepitskii I. A. Sistema khozyaistvennykh prestuplenii. M., 2005. \{Elektronnyi resurs\} Dostup iz sprav. - pravovoi sistemy PS «Konsul'tantPlyus».

11. Kostin A. V. Otsenka ubytkov pravoobladatelei tovarnykh znakov ot kontrafaktsii. diss. kand. yurid. nauk. M. 2009. S. 3. 
12. Kommentarii k postanovleniyam Plenuma Verkhovnogo Suda Rossiiskoi Federatsii po ugolovnym delam (2-e izdanie, pererabotannoe i dopolnennoe) (pod red. M. V. Lebedeva) NORMA, 2008.

13. Korobeev A. I. Sovremennaya rossiiskaya ugolovno-pravovaya politika: vyalotekushchaya evolyutsiya ili radikal'noe reformirovanie ugolovnogo zakonodatel'stva?/ Ugolovnaya politika i pravo v epokhu peremen. Materialy mezhdunarodnoi nauchno-prakticheskoi konferentsii posvyashchennoi pamyati professora P. S. Dagelya. Vladivostok. Izd-vo Dal'nevostochnogo universiteta. 2010. S. 30, 31. 364 s.

14. Kurlyandskii V. I. Ugolovnaya politika: differentsiatsiya i individualizatsiya ugolovnoi otvetstvennosti. V kn.: Osnovnye napravleniya bor'by s prestupnost'yu. S. 81.

15. Luk'yanova V. Yu. K voprosu o pravovoi prirode tekhnicheskikh uslovii // Zakonodatel'stvo i ekonomika. 2014. № 4.

16. Nikitina L.K. Osnovnye napravleniya optimizatsii ugolovnogo zakonodatel'stva ob otvetstvennosti za nezakonnoe ispol'zovanie tovarnogo znaka. Obshchestvo i pravo. 2010, № 1. S. 172-177.

17. O sostoyanii pravovoi okhrany i zashchity intellektual'noi sobstvennosti v Rossiiskoi Federatsii v 2008 godu. Analiticheskii doklad / pod red. d-ra yurid. nauk V. N. Lopatina, M., RNIIIS, 2009, $325 \mathrm{~S}$.

18. O sostoyanii pravovoi okhrany i zashchity intellektual'noi sobstvennosti v Rossiiskoi Federatsii v 2010 godu. Analiticheskii doklad /pod red. Lopatina V. N. M. Izdatel'stvo Soveta Federatsii, 2009.S. 307. $438 \mathrm{~s}$.

19. Po dannym ofitsial'nogo Internet-saita Ministerstva vnutrennikh del RF. URL: http://www.mvd. ru (data obrashcheniya: 12.03.2014).

20. Prozumentov L. M. Kriminologicheskie usloviya kriminalizatsii i dekriminalizatsii. Vestnik Tomskogo Gosudarstvennogo Universiteta. 2012. № 4 (6)

21. http://www.sarmat-tm.ru. Zapros proizvodilsya 6 iyunya 2014 goda

22. Ugolovnyi kodeks Kitaiskoi Narodnoi Respubliki /Pod red. A. I. Korobeeva. perevod D. V. Vichikova SPb.: Yuridicheskii tsentr Press. 2001. S. 147-148.

23. Federal'nyi zakon ot 17.11.2001№ 144-FZ «O vnesenii izmenenii i dopolnenii v Ugolovnyi kodeks Rossiiskoi Federatsii i Ugolovno-protsessual'nyi kodeks RSFSR» «Rossiiskaya gazeta», 2001. № 227. 